\title{
A novel leptin receptor antagonist uncouples leptin's metabolic and immune functions
}

\author{
Lennart Zabeau ${ }^{1}$. Joris Wauman ${ }^{1}$. Julie Dam ${ }^{2}$. Sandra Van Lint ${ }^{1}$ - Elianne Burg ${ }^{1}$. Jennifer De Geest ${ }^{1}$. Elke Rogge ${ }^{1}$. \\ Anisia Silva $^{2} \cdot$ Ralf Jockers $^{2} \cdot$ Jan Tavernier ${ }^{1}$
}

Received: 29 June 2018 / Revised: 28 December 2018 / Accepted: 2 January 2019 / Published online: 18 January 2019

(c) The Author(s) 2019

\begin{abstract}
Leptin links body energy stores to high energy demanding processes like reproduction and immunity. Based on leptin's role in autoimmune diseases and cancer, several leptin and leptin receptor (LR) antagonists have been developed, but these intrinsically lead to unwanted weight gain. Here, we report on the uncoupling of leptin's metabolic and immune functions based on the cross talk with the epidermal growth factor receptor (EGFR). We show that both receptors spontaneously interact and, remarkably, that this complex can partially overrule the lack of LR activation by a leptin antagonistic mutein. Moreover, this leptin mutant induces EGFR phosphorylation comparable to wild-type leptin. Exploiting this non-canonical leptin signalling pathway, we identified a camelid single-domain antibody that selectively inhibits this LR-EGFR cross talk without interfering with homotypic LR signalling. Administration in vivo showed that this single-domain antibody did not interfere with leptin's metabolic functions, but could reverse the leptin-driven protection against starvation-induced thymic and splenic atrophy. These findings offer new opportunities for the design and clinical application of selective leptin and LR antagonists that avoid unwanted metabolic side effects.
\end{abstract}

Keywords Leptin · Leptin receptor · Receptor cross talk · Uncoupling · Metabolism · Immunity

$\begin{array}{ll}\text { Abbreviations } \\ \text { BiFC } & \text { Bimolecular fluorescence complementation } \\ \text { BRET } & \text { Bioluminescence resonance energy transfer } \\ \text { CRH } & \text { Cytokine receptor homology } \\ \text { EGFR } & \text { Epidermal growth factor receptor } \\ \text { Epo } & \text { Erythropoietin } \\ \text { ER } & \text { Endoplasmic reticulum } \\ \text { ERalpha } & \text { Estrogen receptor-alpha }\end{array}$

Electronic supplementary material The online version of this article (https://doi.org/10.1007/s00018-019-03004-9) contains supplementary material, which is available to authorized users.

Lennart Zabeau and Joris Wauman are shared first authors.

Jan Tavernier

jan.tavernier@vib-ugent.be

1 Faculty of Medicine and Health Sciences, VIB-UGent Center for Medical Biotechnology, Flanders Institute for Biotechnology, Ghent University, A. Baertsoenkaai 3, 9000 Ghent, Belgium

2 Inserm U1016, CNRS UMR 8104, Univ. Paris Descartes, Sorbonne Paris Cité, Institut Cochin, 22 rue Méchain, 75014 Paris, France

$\begin{array}{ll}\text { FN III } & \text { Fibronectin type III } \\ \text { FRET } & \text { Fluorescence resonance energy transfer } \\ \text { G-CSF } & \text { Granulocyte-colony stimulating factor } \\ \text { GH } & \text { Growth hormone } \\ \text { gp130 } & \text { Glycoprotein 130 } \\ \text { IGD } & \text { Immunoglobulin-like domain } \\ \text { IGF-IR } & \text { Insulin-like growth factor-I receptor } \\ \text { IL-6 } & \text { Interleukin-6 } \\ \text { KISS } & \text { Kinase substrate sensor } \\ \text { LR } & \text { Leptin receptor } \\ \text { LRP } & \text { Lipoprotein receptor-related protein } \\ \text { MAPK } & \text { Mitogen-activated kinase } \\ \text { PEG } & \text { Polyethylene glycol } \\ \text { PI3K } & \text { Phosphatidylinositide 3-kinase } \\ \text { rPAP } & \text { Rat pancreatitis associated protein } \\ \text { SEAP } & \text { Secreted alkaline phosphatase } \\ \text { STAT } & \text { Signal transducer and activator of } \\ & \text { transcription } \\ \text { TGF-alpha } & \text { Transforming growth factor-alpha } \\ \text { TNF } & \text { Tumour necrosis factor } \\ \text { TR-FRET } & \text { Time-resolved fluorescence energy transfer } \\ \text { VEGF } & \text { Vascular endothelial growth factor } \\ \text { VHH } & \text { Variable domain of heavy chain antibody }\end{array}$




\section{Introduction}

The crucial role of leptin in long-term body weight control is well established. This cytokine with hormone-like characteristics is mainly, but not exclusively, produced and secreted by adipocytes, and plasma leptin levels positively correlate with body fat energy stores $[1,2]$. Loss-of-function mutations in the leptin-encoding $o b$ gene give rise to a complex syndrome that includes not only morbid obesity, but also abnormalities in lipid and glucose metabolism [3], haematopoiesis [4], innate and adaptive immunity (leading to increased risk of infection in mice and men) [5-9], reproduction [10], development [11], angiogenesis [12], vascular remodelling [13], blood pressure [14], and bone formation [15]. Indeed, leptin is more than just a satiety signal and rather acts as a 'metabolic switch' that connects the body's energy stores to high energy demanding processes like immunity and reproduction $[16,17]$. In innate immunity, leptin promotes secretion of inflammatory cytokines and the activation of macrophages, neutrophils and natural killer cells [18]. Functions in adaptive immunity include thymic homeostasis, naïve $\mathrm{CD} 4^{+}$cell proliferation, promotion of $\mathrm{T}$ helper $1\left(\mathrm{~T}_{\mathrm{H}} 1\right)$ responses and suppression of $\mathrm{CD} 4{ }^{+} \mathrm{CD} 25^{\text {high }}$ regulatory $\mathrm{T}$ cells (Tregs) [18]. Consequently, leptin can contribute to the onset and progression of several $\mathrm{T}$ cell-controlled autoimmune diseases, including Crohn's disease [19, 20], rheumatoid arthritis [21, 22], multiple sclerosis [23, 24] and autoimmune hepatitis [25-27]. Furthermore, clinical reports unequivocally link elevated serum leptin levels (caused by obesity) to an increased risk of certain cancers including prostate [28], breast [29, 30], colorectal [31], renal cancers [32] and multiple myeloma [33, 34].

Leptin mediates its effects upon binding and activation of the single-membrane spanning leptin receptor (LR), encoded by the $d b$ gene [35], and belonging to the class I cytokine receptor family. Its ectodomain is composed of two cytokine receptor homology (CRH1 and CRH2) domains, which are separated by an immunoglobulin-like domain (IGD) and is followed by two membrane-proximal fibronectin type III (FN III) domains. The CRH2 domain is necessary and sufficient for leptin binding [36, 37], but functional receptor clustering requires interaction with the IGD since leptin site III mutants that fail to contact this domain behave as leptin antagonists [38, 39]. Like all class I cytokine receptors, the LR lacks intrinsic kinase activity and relies for signalling on constitutively associated Janus tyrosine kinases (JAKs) [40]. LR clustering results in JAK trans-phosphorylation and activation of several intracellular signalling cascades including the STAT (signal transducer and activator of transcription), MAPK (mitogen-activated protein kinase), PI3K (phosphatidylinositide 3-kinases) and mTOR pathways [41, 42].
In a recent study, we demonstrated the possible uncoupling of leptin's metabolic and immune functions at the LR level [43]. Indeed, the interaction between leptin's site III (consisting of residues S120 and T121) and the LR IGD domain is strictly necessary for the control of body weight and metabolism, but is dispensable for immune signalling. We hypothesised that this non-canonical LR signalling may depend on receptor cross talk mechanisms, as documented for the insulin-like growth factor-I receptor (IGFIR) $[44,45]$, epidermal growth factor receptor (EGFR) $[46,47]$ or the estrogen receptor-alpha $(\mathrm{ER} \alpha)[48,49]$.

Here, we identified a cross talk between LR and EGFR, defined the structural requirements for this cross talk and used this information to design a LR antagonist that selectively interferes with the immunomodulatory effects of leptin without interfering with the canonical LR signalling that controls the metabolic function.

\section{Materials and methods}

\section{Cell culture, transfection and reagents}

Hek293T (human embryonic kidney) cells (ATCC) were grown in DMEM (Dulbecco's modified Eagle's medium; Gibco, life technologies) with $4500 \mathrm{mg} / \mathrm{l}$ glucose and $10 \%$ FCS (foetal calf serum; Invitrogen) in a $10 \% \mathrm{CO}_{2}$ humidified atmosphere at $37{ }^{\circ} \mathrm{C}$. Cells were transfected with standard calcium phosphate precipitation. Recombinant mouse leptin and leptin S120A-T121A were purified and refolded from $E$. coli inclusion bodies [50]. To prolong the half-life in circulation, leptin was pegylated with a $40 \mathrm{kDa}$ PEG (polyethylene glycol) variant (Sunbright) according to the manufacturer's instructions. Generation and screening of a mouse leptin receptor-specific VHH library has been described previously [50]. Mono- and bispecific (genetically fused to the sequence of anti-mouse serum albumin (mAlb) via a flexible GGS-linker) VHHs were cloned in the pHEN6C vector for periplasmic $E$. coli expression. Proteins were purified after osmotic shock using the $\mathrm{C}$-terminal 6*His-tag with the TALON metal affinity resin (Clontech). Imidazole (Merck) was used for elution and removed using PD-10 gel filtration columns (GE Healthcare). Protein concentrations were determined using the absorbance at $280 \mathrm{~nm}$ (Nanodrop; ThermoFisher Scientific) and purity via SDSPAGE. Endotoxins were washed away during purification with 0.5\% EMPIGEN (Calbiochem, Millipore) and 0.5\% CHAPS (Sigma-Aldrich) and afterwards quantified using limulus amoebocyte lysate (LAL) QCL-1000 (Lonza). If still present, endotoxins were removed using Pierce Endotoxin Removal Resin (Thermo Scientific). 


\section{Co-immunoprecipitation}

Hek293T cells were transfected with tagged EGFR, LR, LR-FATT variants or combinations thereof. $24 \mathrm{~h}$ later, cells were lysed in modified RIPA buffer and cleared lysates were subjected to immunoprecipitation with anti-FLAG M2 affinity resin (Sigma). Proteins in cell lysates (input) and after co-immunoprecipitation were analysed using SDS-PAGE and Western blotting using mouse anti-FLAG (Sigma) and mouse anti-E-tag antibodies (Bethyl), diluted according to the manufacturer's guidelines in StartingBlock blocking buffer (Pierce) supplemented with $0.1 \%$ Tween-20, and revealed using the SuperSignal West Pico Chemiluminescent Substrate (Pierce) after incubation with HRP-conjugated anti-mouse secondary antibody (Jackson ImmunoResearch).

\section{Luciferase reporter assay}

Hek293T cells were transiently transfected with (a combination of) receptors and the STAT3-responsive pXP2d2-rPAP1 (rat pancreatitis associated protein 1)-luciferase reporter [51]. Transfected cells were stimulated overnight as indicated. Cell lysates were prepared [lysis buffer: $25 \mathrm{mM}$ Tris/ HCL, pH 7.8, 2 mM EDTA, 2 mM DTT (dithiothreitol), $10 \%$ glycerol and $1 \%$ Triton X-100], and $35 \mu$ of luciferase substrate buffer [20 mM Tricine, $1.07 \mathrm{mM}\left(\mathrm{MgCO}_{3}\right)_{4}$ $\mathrm{Mg}(\mathrm{OH})_{2} \cdot 5 \mathrm{H}_{2} \mathrm{O}, 2.67 \mathrm{mM} \mathrm{MgSO}{ }_{4} \cdot 7 \mathrm{H}_{2} \mathrm{O}, 0.1 \mathrm{mM}$ EDTA, $33.3 \mathrm{mM}$ DTT, $270 \mu \mathrm{M}$ coenzyme A, $470 \mu \mathrm{M}$ luciferin and $530 \mu \mathrm{M}$ ATP, final $\mathrm{pH}$ 7.8] was added per $50 \mu \mathrm{l}$ of lysate. Light emission was measured for $5 \mathrm{~s}$ in a TopCount chemiluminescence counter (Packard).

\section{EGFR phosphorylation}

EGFR phosphorylation was analysed in transfected Hek293T cells that were serum starved overnight and left untreated or stimulated with indicated amounts of leptin or leptin antagonist for $5 \mathrm{~min}$. Lysates were prepared in Laemmli loading buffer and proteins were blotted overnight. Phosphorylated and total protein levels were visualised using rabbit antiphospho-EGFR (Tyr1068) or EGFR antibodies (both Cell Signalling Technology) and an HRP-conjugated anti-rabbit secondary antibody (Jackson ImmunoResearch) as described earlier.

\section{Time-resolved fluorescence energy transfer (TR-FRET) measurement}

The TR-FRET saturation curve is generated in conditions where the expression of the energy donor (EGFR) is kept constant with increasing expression of the energy acceptor (LR) $[52,53]$. Hek293 cells were therefore transfected with plasmid vectors encoding SNAP-tagged EGFR (10 ng), and HALO-tagged LR (0-170 ng) constructs (completed to $200 \mathrm{ng} /$ well of 96-well plate with noncoding plasmid) were plated in polyornithine-coated 96-well white plates. Two days after transfection, adherent cells were washed and incubated with Taglite buffer (Cisbio Bioassay) containing $200 \mathrm{nM}$ HALO-Tb and/or SNAP-d2 or SNAP-Tb substrates (Cisbio Bioassay) for $1 \mathrm{~h}$ at $4{ }^{\circ} \mathrm{C}$. Cells were washed four times with Taglite buffer and the fluorescence of Lumi4-Tb (excitation at $340 \mathrm{~nm}$, emission at $620 \mathrm{~nm}, 150 \mu$ s delay, and $500 \mu$ s integration time) and the TR-FRET signals ( $340 \mathrm{~nm}$, $665 \mathrm{~nm}, 150 \mu \mathrm{s}$, and $500 \mu \mathrm{s}$ ) were read using an Infinite F500 spectrofluorimeter (Tecan). Background signals were measured on cells transfected with empty vectors and subtracted to obtain the specific signal.

\section{Kinase substrate sensor (KISS) experiments}

The extracellular and transmembrane domains of the EGFR, LR, LR-FATT and the granulocyte-colony stimulating factor receptor (G-CSFR) were fused as prey proteins to the cytoplasmic tail of glycoprotein 130 (gp130), or as bait proteins to a C-terminal fragment of human Tyk2 (Aa 589-1187) as described in [54]. In a standard KISS experiment, combinations of equal amounts of bait and prey DNAs together with the STAT3 responsive pXP2d2-rPAP1-luciferase reporter were transiently transfected in Hek293T cells [54]. Luciferase activity was measured 2 days after transfection as described earlier.

\section{Plate-binding assays}

\section{Domain mapping}

Specificity of the different VHHs was determined in a plate-binding assay using a series of mouse LR extracellular subdomains (or a combination thereof) fused to secreted alkaline phosphatase (SEAP) [50]. VHHs were bound via a penta-His antibody (Qiagen) on Maxisorp plates (Costar). Excess unbound VHH was washed away with washing buffer (PBS + 0.05\% Tween-20) and plates were blocked (PBS $+0.1 \%$ Casein) and further incubated with conditioned medium containing LR-SEAP fusions for $2 \mathrm{~h}$ at room temperature. After 4 successive washes, bound SEAP activity was measured using the chemiluminescent CSPD substrate (PhosphaLight, Tropix) in a TopCount chemiluminescence counter (Canberra Packard).

\section{Affinity measurements}

Affinities of the different VHHs for the LR were determined in a similar plate-binding assay as described before: VHH-coated plates were incubated with a serial dilution of the mouse LR extracellular domain fused to SEAP 
a

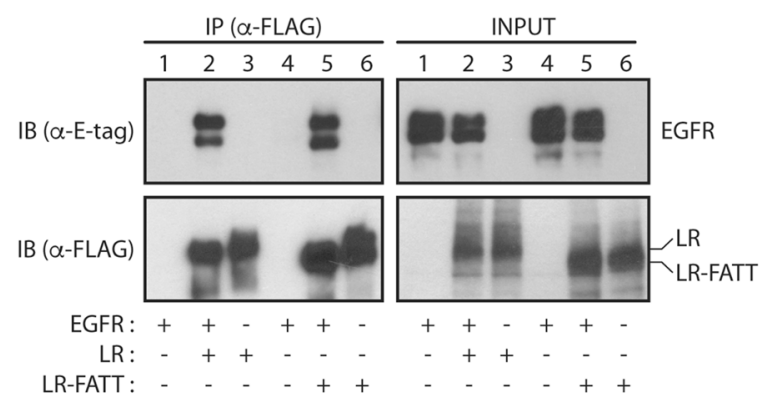

C
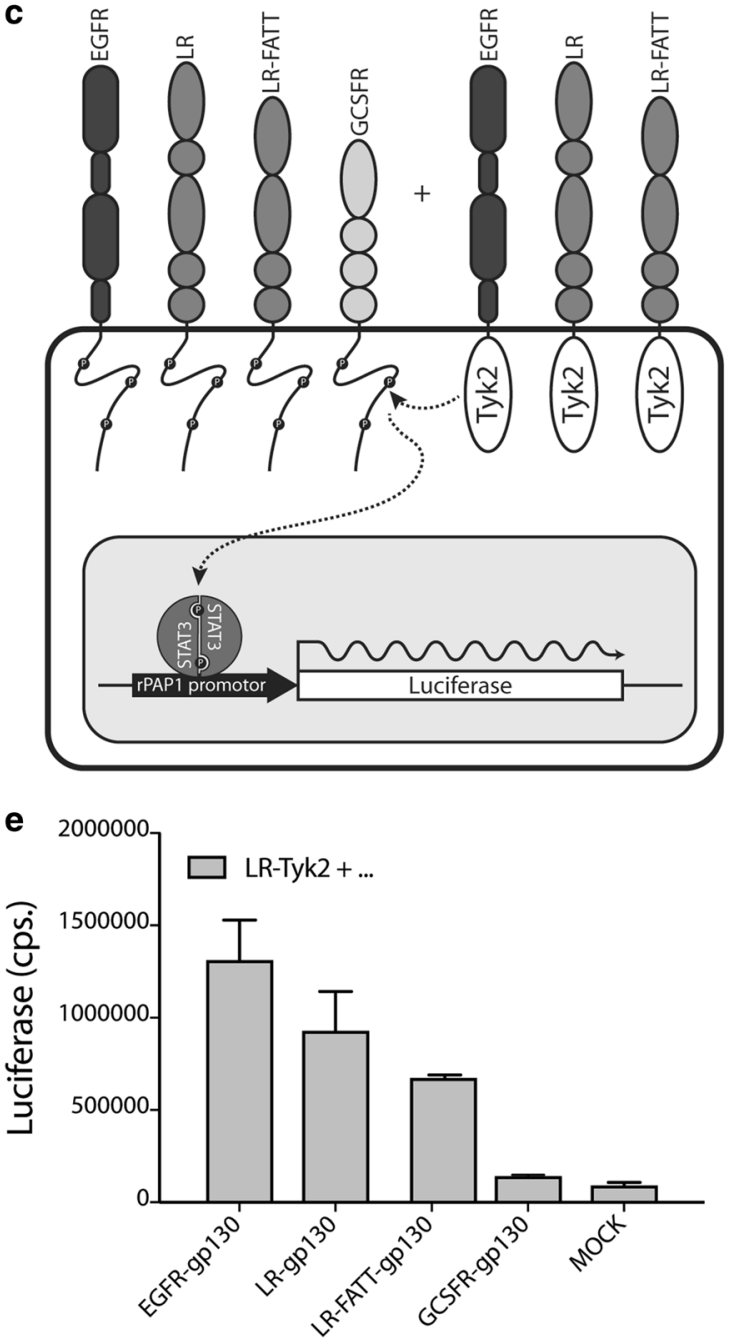

( $\mathrm{mLR}_{\mathrm{EC}}$-SEAP) [50] for $2 \mathrm{~h}$. The GraphPad Prism software was used to calculate the affinities from the bound SEAP measurements.

\section{Serum VHH quantification}

Penta-His-coated plates were incubated with a serial dilution of purified VHH as a standard, or a 1:1000 dilution of mouse b

\begin{tabular}{|c|c|c|c|}
\hline & vehicle & Leptin & Leptin S120A T121A \\
\hline Bmax & 21003 & 17720 & 18301 \\
\hline Kd & 0.1420 & 0.1639 & 0.1716 \\
\hline
\end{tabular}
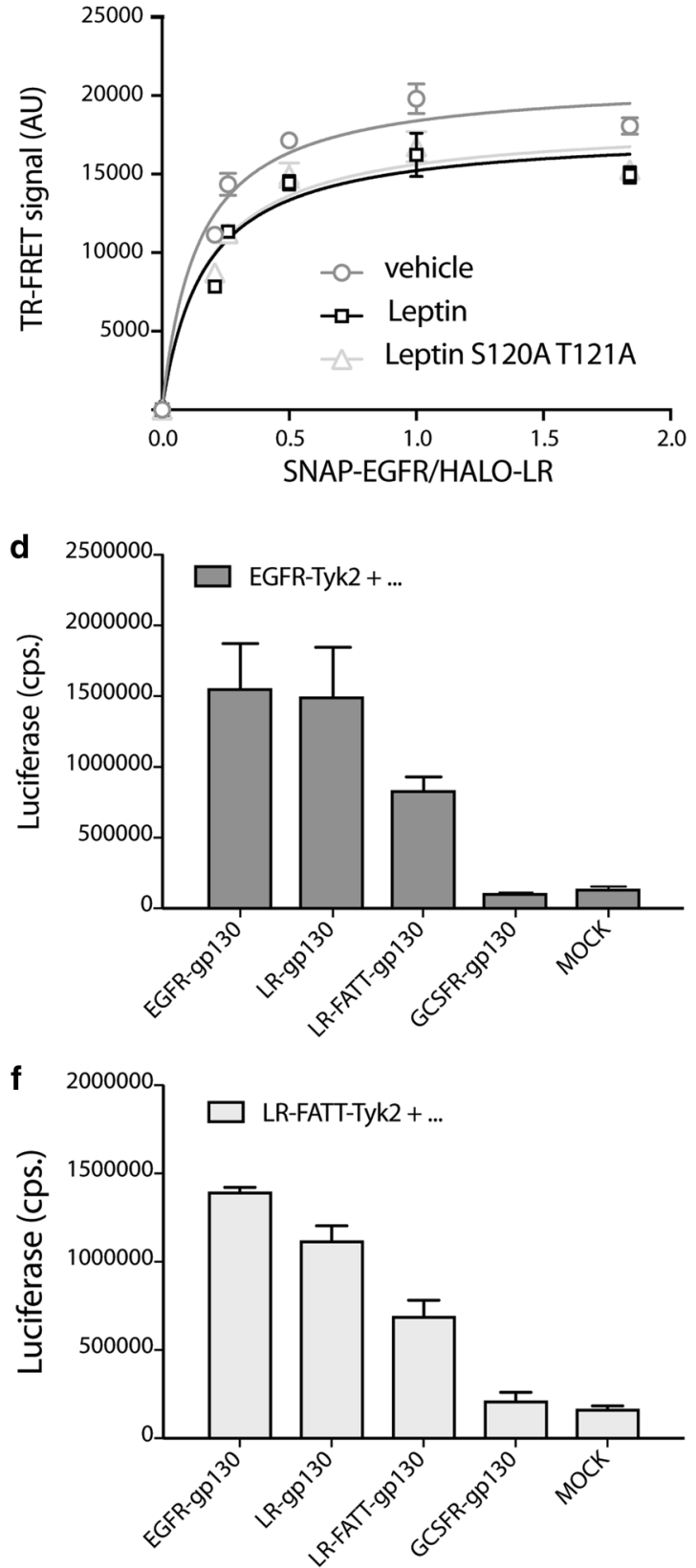

serum samples for $2 \mathrm{~h}$, and subsequently allowed to bind mLR $_{\text {EC }}$-SEAP. Serum VHH concentrations were calculated from the standard curves using the GraphPad Prism software. 
4Fig. 1 Ligand-independent EGFR-LR clustering does not require the LR IGD domain. a EGFR, EGFR + LR/LR-FATT, or LR/LR-FATT transfected cells were lysed and subjected to immunoprecipitation with anti-FLAG beads. Proteins in lysates or after immunoprecipitation were analysed with anti-E-tag and anti-FLAG antibodies in Western blot. b TR-FRET saturation experiment assessing the heterooligomerization between LR and EGFR at the cell surface of adherent Hek293 cells. TR-FRET intensity at the cell surface, measured in Hek293 cells expressing SNAP-EGFR (labelled with the non-permeable membrane SNAP-Tb substrate) with increasing concentration of HALO-LR (labelled with the non-permeable membrane HALOd2 substrate), shows a saturation curve reflecting close proximity between HALO-LR and SNAP-EGFR at the cell surface. Stimulation with both leptin and leptin S120A/T121A modifies the TR-FRET signal between LR and EGFR without modification of the TR-FRET 50 value, suggesting a ligand-induced change of conformation within the hetero-oligomer. $\mathbf{c}$ Schematic presentation of the KISS setup. $\mathbf{d}-\mathbf{f}$ Hek293T cells were transfected with d EGFR-Tyk2, e LR-Tyk2, or f LR-FATT-Tyk2 in combination with gp130 fusion proteins and the STAT3-responsive rPAP1 luciferase reporter. $24 \mathrm{~h}$ after transfection, cells were resuspended, seeded in a 96-well plate and cultivated for 2 more days. Data points are the mean $( \pm$ STDEV) of quadruple luciferase measurements (cps: counts/s). Both datasets are representative for at least three independent experiments

\section{In vivo experiments}

Mice were maintained in pathogen-free conditions in a temperature-controlled environment with $12 / 12 \mathrm{~h}$ light/dark cycles and received food and water ad libitum.

To evaluate the metabolic effects, 8 -week-old female C57BL/6 mice were treated with $200 \mu \mathrm{g} /$ mouse/day of mAlb fusions of the selected VHHs intraperitoneally (i.p.) or with PBS for 2 weeks. On a daily basis, animals were weighed and food intake (average food intake per cage/number of mice in cage) and body temperature were monitored. At the end of the experiment, blood was collected for the measurement of VHH concentrations (see above) and serum leptin levels using the mouse leptin DuoSet ELISA (R\&D Systems Europe Ltd). Further haematological analysis was performed using a Hemavet 950FS (Drew Scientific) whole blood counter. From each group, one mouse was used for a glucose tolerance test: mice were fasted for 6 h, i.p. injected with $2 \mathrm{~g}$ glucose/ $\mathrm{kg}$ body weight and glucose levels were measured from tail vein blood at the indicated time points using AlphaTRAK 2 Blood Glucose Test Strips (Abbott). After animals were killed via $\mathrm{CO}_{2}$ asphyxiation, subcutaneous and visceral fat tissue was dissected and weighed.

To evaluate immune-related effects, 8 -week-old male C57BL/6 mice were fed ad libitum or starved for $48 \mathrm{~h}$. The latter group either received a daily i.p. injection of PBS, pegylated leptin (50 $\mu \mathrm{g} / \mathrm{mouse} /$ day $)$ or a combination of pegylated leptin $(50 \mu \mathrm{g} /$ mouse/day $)$ and $4.80-\mathrm{mAlb}$ ( $200 \mu \mathrm{g} / \mathrm{mouse} /$ day). At the end of the experiment, animals were killed via $\mathrm{CO}_{2}$ asphyxiation and spleen and thymi were isolated. Organs were weighed and the number of white blood cell, lymphocytes, neutrophils and monocytes in homogenates were quantified using the Hemavet 950FS (Drew Scientific) according to the manufacturer's guidelines.

\section{Statistical analysis}

Data were analysed with the GraphPad PRISM software using one-way ANOVA followed by Tukey multiple-comparison tests. Results with $P$ value less than 0.05 were considered statistically significant.

\section{Results}

\section{Ligand-independent LR-EGFR clustering}

We hypothesised that non-canonical LR signalling (i.e. independent of a correct leptin site III-IGD interaction) might be achieved via cross talk with other receptors like the EGFR. Therefore, we evaluated the role of the IGD in ligand-independent clustering of the LR and EGFR using co-immunoprecipitation, TR-FRET [52, 53] and the mammalian two-hybrid KISS method [54]. In the first setup, we compared the ability of LR-FLAG or LR-FATTFLAG to precipitate E-tagged EGFR when co-expressed in Hek293T cells. LR-FATT originates from a spontaneous splice mutation causing deletion of the complete LR IGD in all LR isoforms [43]. The observation that both LR and LR-FATT are able to pull down the EGFR (Fig. 1a) indicates that the interaction between both receptors is independent of the presence of LR IGD. To further support the LR-EGFR interaction, we performed additional TR-FRET and KISS experiments in living cells. TR-FRET intensity at the cell surface of Hek293 cells expressing SNAP-tagged EGFR (labelled with the non-permeable membrane SNAP-d2 substrate) with increasing concentration of HALO-tagged LR (labelled with the non-permeable membrane HALO-Tb substrate), shows a saturation curve reflecting close proximity between SNAP-EGFR and HALO-LR at the cell surface (Fig. 1b). In line with the latter, imaging of both receptors expressed in HeLa cells showed co-localisation between cell surface labelled LR and EGFR (Supplementary Figure 1). Both wild-type leptin and leptin S120A/T121A similarly decrease the TR-FRET signal without changing the TR-FRET ${ }_{50}$ value, suggesting that both ligands induce a similar conformational change within the complex (Fig. 1b). In the KISS approach, the extracellular domains of EGFR, LR, LRFATT or the negative control G-CSFR were fused to the cytoplasmic tails of gp130 or to the kinase and kinaselike domain of Tyk2 (Fig. 1c). The resulting constructs were co-transfected with a STAT3 responsive rPAP1 luciferase reporter which allows detection of the interaction between a gp130- and Tyk2-fused receptor chain 
upon reconstitution of STAT3 signalling. Luciferase data in Fig. 1d-f clearly illustrate that both EGFR and LR form homo-oligomers on the membrane, but also cluster with each other in the absence of any ligand, and that, in accordance with the co-immunoprecipitation data, this clustering does not depend on the LR IGD.

\section{Effect of EGFR on non-canonical LR signalling}

The leptin S120A-T121A site III mutant is unable to interact with the LR IGD and therefore unable to initiate canonical JAK2-STAT3 signalling ([38] and Fig. 2b). However, we found that both wild-type leptin and the antagonistic leptin mutein S120A-T121A are able to induce EGFR phosphorylation in a dose-dependent manner in cells expressing both receptors (Fig. 2a). Furthermore, coexpression of the EGFR partially restores signalling of leptin mutein S120A-T121A in a STAT3-responsive luciferase reporter assay (Fig. 2b). In contrast, we could not observe a significant difference in STAT3 signalling mediated by wild-type leptin in LR or LR + EGFR transfected cells (Fig. 2c).

\section{Interfering with LR-EGFR cross talk}

In a previous study, we evaluated a library of LR-specific VHHs for their effect on leptin binding and STAT3-dependent LR signalling [50]. We found that IGD, CRH2, and FN III-specific VHHs can neutralise LR signalling, while only certain CRH2 VHHs can block leptin binding to its receptor. The experimental setup in which the leptin S120A-T121A mutant is able to generate a STAT3-dependent signal in LR-EGFR co-expressing cells (Fig. 2b) prompted us to rescreen this library for binders that could selectively interfere with this LR-EGFR cross talk. VHH 2.17, which blocks the CRH2-leptin interaction [50] interfered, as expected, with both LR and LR-EGFR signalling (Fig. 3a, b). Interestingly, VHH 4.80 specifically interfered with LR-EGFR signalling (Fig. 3b), but not with canonical LR receptor activation (Fig. 3a). In line with the STAT3-dependent reporter data, VHH 4.80 was able to dose-dependently interfere with both wild-type leptin and leptin S120A-T121A-induced EGFR phosphorylation (Fig. 3c).

We applied a plate-binding assay using a $\mathrm{mLR}_{\mathrm{EC}}$-SEAP fusion protein to determine the affinity of the different VHHs. Figure 3d shows that VHH 4.80 binds the receptor with low nanomolar affinity $(0.47 \pm 0.017 \mathrm{nM})$ comparable to VHH $2.17(0.544 \pm 0.065 \mathrm{nM})$ and VHH 4.10 (a neutralising IGD-specific VHH; $0.66 \pm 0.029 \mathrm{nM})$. A similar platebinding assay using different LR subdomains or combinations thereof was then used to show that VHH 4.80 binds to
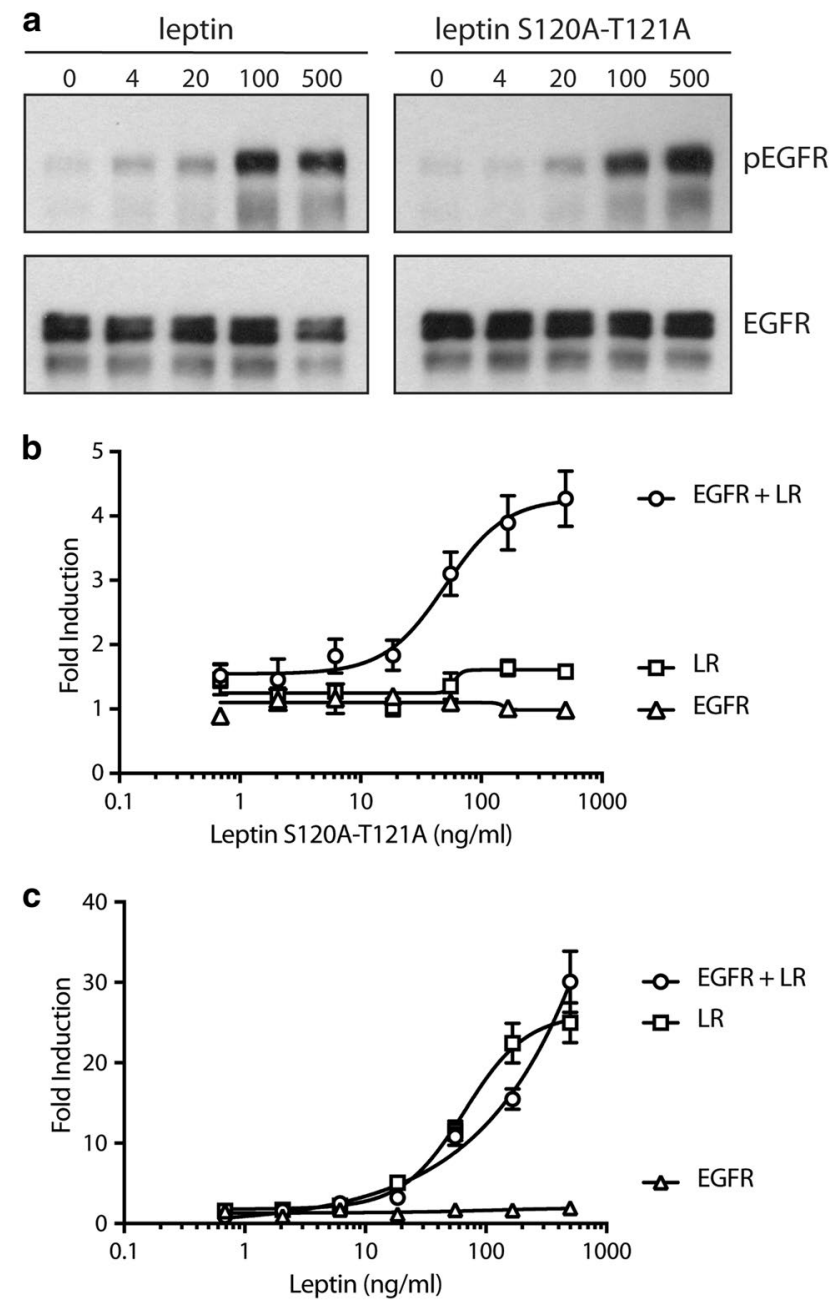

Fig. 2 EGFR allows IGD-independent LR signalling. a EGFR + LR transfected cells were serum starved overnight, stimulated for $5 \mathrm{~min}$ with a serial dilution wild-type or mutant leptin and lysed. Lysates were blotted onto a nitrocellulose membrane and analysed using antibodies specific for phosphorylated (Y1068) EGFR or total EGFR. b, c EGFR, LR, or the combination, were co-transfected with the rPAP1 luciferase reporter in Hek293T cells. Two days after transfection, cells were stimulated with a serial dilution of leptin S120A-T121A (b) or wild-type leptin (c) as indicated. Mean luciferase counts $( \pm$ STDEV.) of quadruple measurements are plotted. Both datasets are representative for at least three independent experiments

the LR FN III domains (Fig. 3e). VHHs 2.17 and 4.10 only bind CRH2 or IGD containing chimeras, respectively.

\section{Effect of VHH 4.80 on metabolism}

VHH 2.17 (CRH2 specific) and 4.10 (IGD specific) both interfere with canonical LR signalling and thus leptin's metabolic functions as evidenced by the in vivo increase in body weight and other metabolic parameters like fat pads, insulin and glucose levels [50]. In a next experiment, we compared the effects of VHH 4.80 on metabolic parameters 

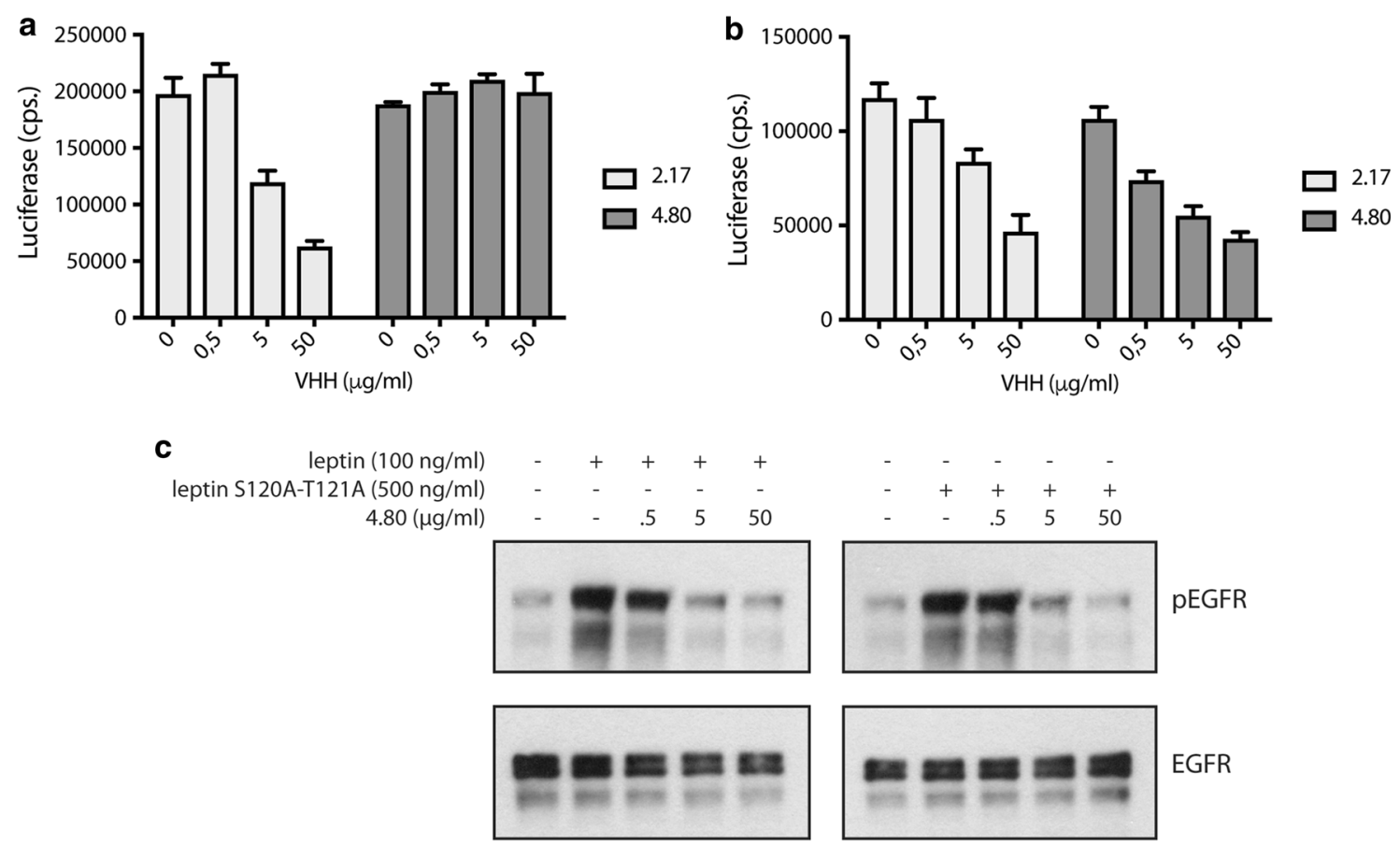
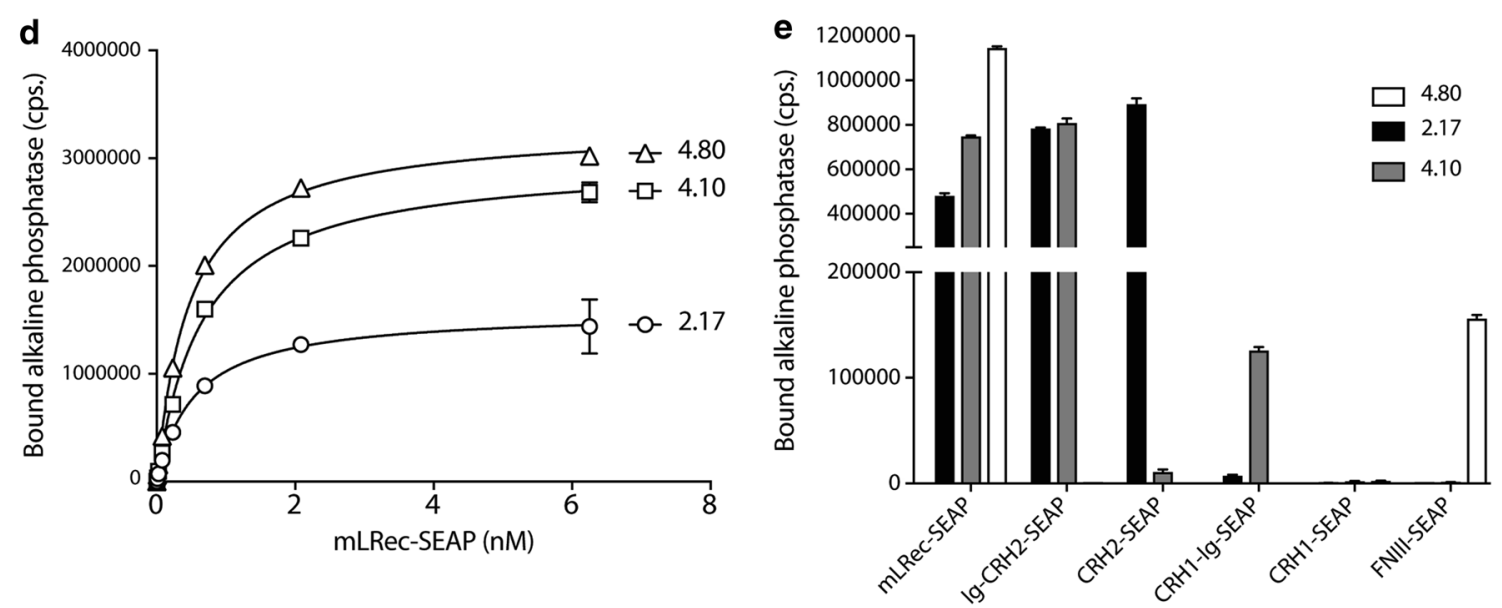

Fig. 3 VHH 4.80 selectively interferes with EGFR-LR cross talk, but not with canonical LR signalling. LR (a) or EGFR + LR (b) expressing cells were stimulated with wild-type leptin or leptin S120AT121A, respectively, in the presence of a serial dilution 2.17 or 4.80 VHH. Mean luciferase values $( \pm$ STDEV) of triplicate measurements are plotted. c EGFR + LR transfected were stimulated with a sub-optimal concentration of wild-type leptin $(100 \mathrm{ng} / \mathrm{ml})$ or leptin S120A-T121A $(500 \mathrm{ng} / \mathrm{ml})$ in the presence of increasing concentra-

with the other two VHHs . To prolong half-life in circulation, VHHs were genetically fused to a VHH directed against mouse serum albumin (mAlb) [50]. Healthy mice were treated with the resulting bispecific VHHs on a daily basis and food intake and body weight were measured throughout the duration of the experiment. Data in Fig. 4a and $\mathrm{b}$ show that treatment with 2.17-mAlb and 4.10-mAlb resulted in a significant increase in food intake and body tions of 4.80 VHH. Phosphorylated and total EGFR levels were visualised using Western blot with specific antibodies. d Plates coated with VHH 2.17, 4.10 or 4.80 were incubated with a serial dilution of $\mathrm{LR}_{\mathrm{EC}}$-SEAP fusion protein. Bound alkaline phosphatase activity $( \pm$ STDEV) of triplicate measurements is plotted. e Specificity of VHHs is determined in a similar manner using SEAP fusion proteins of LR sub-domains

weight, while 4.80-mAlb does not seem to have any effect. Mice were killed on day 14 and fat pads (subcutaneous and visceral) were dissected and weighed. 4.80-mAlb treatment did not result in a significant increase in fat mass, and this again was in contrast to the other two VHHs (Fig. 4c, d). Increase in body weight resulted in hyperleptinaemia in the case of 4.10-mAlb, and to a lesser extent 2.17-mAlb, but not in the case of 4.80-mAlb (Fig. 4e). Basal blood glucose 

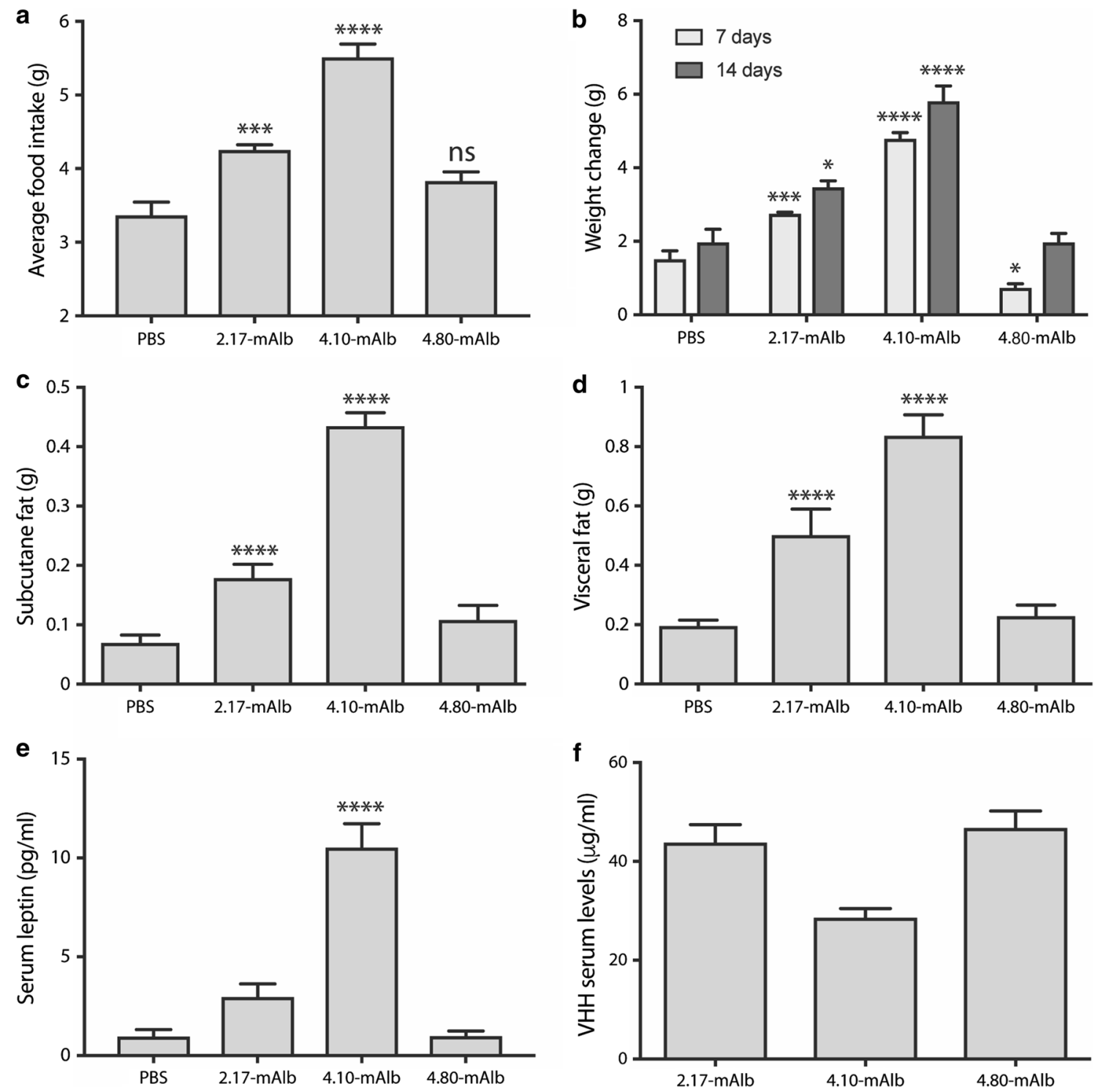

Fig. 4 Effect of LR-specific on metabolism. C57BL/6 mice were i.p. injected daily with PBS $(n=6)$ or $200 \mu \mathrm{g}$ of the mAlb fusions of the LR-specific VHHs 2.17, 4.10 or $4.80(n=6)$ for 2 weeks. Daily average food intake $( \pm$ SEM) was followed (a) and mean body weight changes $( \pm$ SEM) after 7 and 14 days are plotted (b). After 2 weeks, animals were killed and subcutaneous (c) and visceral fat (d) was

isolated and weighed (mean \pm SEM). Serum leptin (e) and VHH (f) levels (mean \pm SEM) were determined as described in "Materials and methods". $* P<0.05, * * P<0.01, * * * P<0.005$, and $* * * * P<0.0001$ compared to PBS treatment. Data are representative for three independent experiments

levels did not differ significantly between the different treatments at the end of the study and there was no difference in glucose tolerance between all treatment groups (Supplementary Figure 2a, b). To exclude the possibility that the lack of effects of 4.80-mAlb on metabolism could be due to a different accumulation in circulation, we used the $\mathrm{mLR}_{\mathrm{EC}}$-SEAP binding assay (see above) to quantify the levels of the bispecific VHHs. Data in Fig. 4f show that 4.80-mAlb $(46.66 \pm 3.50 \mu \mathrm{g} / \mathrm{ml})$ levels are comparable to those of $2.17-\mathrm{mAlb}(43.72 \pm 3.73 \mu \mathrm{g} / \mathrm{ml})$ or $4.10-\mathrm{mAlb}$ $(28.53 \pm 1.72 \mu \mathrm{g} / \mathrm{ml})$. No toxic side effects of the treatments

were observed in respect to body temperature, red blood cell numbers, haematocrit and haemoglobin concentration (Supplementary Figure 3a-d).

\section{Effect of VHH 4.80 on leptin immune signalling}

When white blood cell counts in circulation were measured after 2-week treatments with the VHHs (see earlier), we observed a trend towards lymphopaenia (but not neutropaenia) in mice treated with 4.80-mAlb (Supplementary Figure 4). This suggests a possible effect of VHH 4.80 on 
leptin immune signalling. We therefore examined the effect of the VHH on immune functions in a state of starvation. Starvation is known to negatively affect the weight and cellularity of the immune compartments spleen, thymus and bone marrow [55-57], and this atrophy can be blocked by exogenous administration of leptin $[55,56,58]$. To examine the effect of VHH 4.80 in this experimental setup, 8-weekold mice were starved for $48 \mathrm{~h}$ with or without exogenous administration of pegylated leptin. One group also received intraperitoneal injections of 4.80-mAlb. As expected, data in Fig. 5a-d show that starvation resulted in a decreased weight and cellularity of both spleen and thymus. Leptin administration protected against these effects in most cases, while 4.80-mAlb could, at least in part, prevent this protection. Several splenocytic subpopulations were further characterised and a similar interference of 4.80-mAlb on the leptininduced restoration of lymphocyte, neutrophil and monocyte counts was observed (Fig. 5e-g). These data indicate that 4.80-mAlb interferes with leptin-mediated immune functions. Altogether, our data showed that VHH 4.80 inhibits leptin-mediated LR-EGFR activation and cross talk and that it counteracts leptin-mediated immune responses.

\section{Discussion}

Cytokine receptors often appear as inactive, pre-formed complexes on the cellular surface in the absence of ligands. Well-studied examples include the erythropoietin (Epo) receptor [59], the growth hormone (GH) receptor [60], and the interleukin-6 (IL-6) receptor [61]. Bimolecular fluorescence complementation (BiFC) experiments illustrated not only that all members of the EGFR family form homo- and heterodimers in the absence of their respective ligands, but also that this clustering already occurs in the endoplasmic reticulum (ER) and depends on the intracellular receptor domains $[62,63]$. Similarly, the high basal signal in the absence of leptin in bioluminescence resonance energy transfer (BRET) [64] and FRET [65], and co-immunoprecipitation experiments $[66,67]$ suggest that the LR forms pre-formed dimers (or oligomers) on the cellular surface. This clustering likely involves cysteine residues in the CRH2 domain and, as for the EGFR, already occurs intracellularly [68]. Our co-immunoprecipitation and TR-FRET or adapted KISS experiments in Fig. 1 showed that both the EGFR and LR not only form homodimers (or oligomers), but also heterodimers (or oligomers) with each other on the cellular surface. TR-FRET experiments at the plasma membrane with fluorophores coupled to the N-terminus of the extracellular part of the receptors demonstrate close proximity between the extracellular chains of both receptors (Fig. 1b). Inversely, lack of FRET signal between C-terminal tagged receptors, observed by Eisenberg and colleagues [69], might suggest that the FRET probes on the cytoplasmic domains are likely too distant for the energy transfer. The clustering between LR and EGFR appears to be independent of the LR IGD, since LR-FATT, a naturally occurring and a signallingdeficient LR variant lacking the complete IGD identified in obese fatt/fatt mice [43], is as efficient in immunoprecipitating the EGFR as wild-type LR. Likewise, co-expression of EGFR and LR-FATT KISS bait and prey proteins resulted in clear STAT3-dependent signalling.

The EGFR can be activated by its "natural" ligands (including EGF, transforming growth factor- $\alpha$ (TGF- $\alpha$ ), heparin-binding EGF-like growth factor, amphiregulin, and epiregulin), but also by cross-activation with G-protein-coupled receptors, the tumour necrosis factor receptor (TNFR), or IGF-IR (reviewed in [70-73]). Activation of the EGFR is widely recognised as a potent signal in the regulation of diverse biological processes including cell proliferation, survival and motility, depending on the cellular system, the stimulus and the repertoire of signalling molecules recruited [74]. Likewise, not only leptin binding, but also cross talk with ER $\alpha$, IGF-IR, lipoprotein receptor-related protein 1 and 2 (LRP1 and LRP2), and vascular endothelial growth factor (VEGF) receptor has been reported to activate the LR [41].

Cross talk and cross-activation between LR and EGFR is well documented mainly in cancer cell lines, but also in muscle, salivary gland, and mucosal cells and in rat kidneys (reviewed in [41]). Several of these studies showed reciprocal cross-phosphorylation of both receptors and observed that EGFR inhibitors can inhibit leptin-induced signalling events. Both long and short isoforms of the LR were shown to phosphorylate the EGFR family member ErbB2 (both kinase positive and kinase negative) in a leptin-dependent way, suggesting that this cross-activation is independent of downstream LR signalling [69]. The principal function of EGFR is to regulate epithelial tissue development and homeostasis. In pathological settings, such as lung and breast cancer, the EGFR is a driver of tumourigenesis [75]. Aberrant activation of the EGFR and its downstream pro-oncogenic signalling pathways, such as the MAPK and PI3K pathway, promotes cancer cell proliferation, including their chronic initiation and progression through the cell cycle (reviewed by [76]). Leptin was shown to participate in human breast cancer progression and metastasis [77] and induces, via EGFR phosphorylation, clonogenicity, anchorage-independent growth, migration, Notch activation and survivin upregulation in human breast cancer cells [78], illustrating that this LR-EGFR cross talk also has possible biological implications in the context of EGFR signalling.

The interaction between the LR IGD and leptin's binding site III is essential for the formation of an activated LR complex and downstream signalling. Deletion of this domain results in a receptor completely devoid of biological activity [36, 37]. Likewise, mutation of residues 
Fig. 5 VHH 4.80 blocks leptin protection against starvationinduced splenic and thymic atrophy. C57BL/6 mice were fed ad libitum or were starved for $48 \mathrm{~h}$. Starved animals were injected i.p. at the start of the starvation and $24 \mathrm{~h}$ later with PBS, pegylated leptin or a combination of pegylated leptin and 4.80-mAlb. Animals were killed, thymi (a, b) and spleens $(\mathbf{c}, \mathbf{d})$ isolated and weighed (a, c) and the total number of white blood cells $(\mathbf{b}, \mathbf{d})$, splenic lymphocytes (e), neutrophils

(f) and monocytes (g) counted using the Hemavet instrument. Values represent mean \pm SEM; $* P<0.05, * * P<0.01$, $* * * P<0.005$ vs. ad libitum-fed controls, unless stated otherwise. Data representative for three independent experiments a
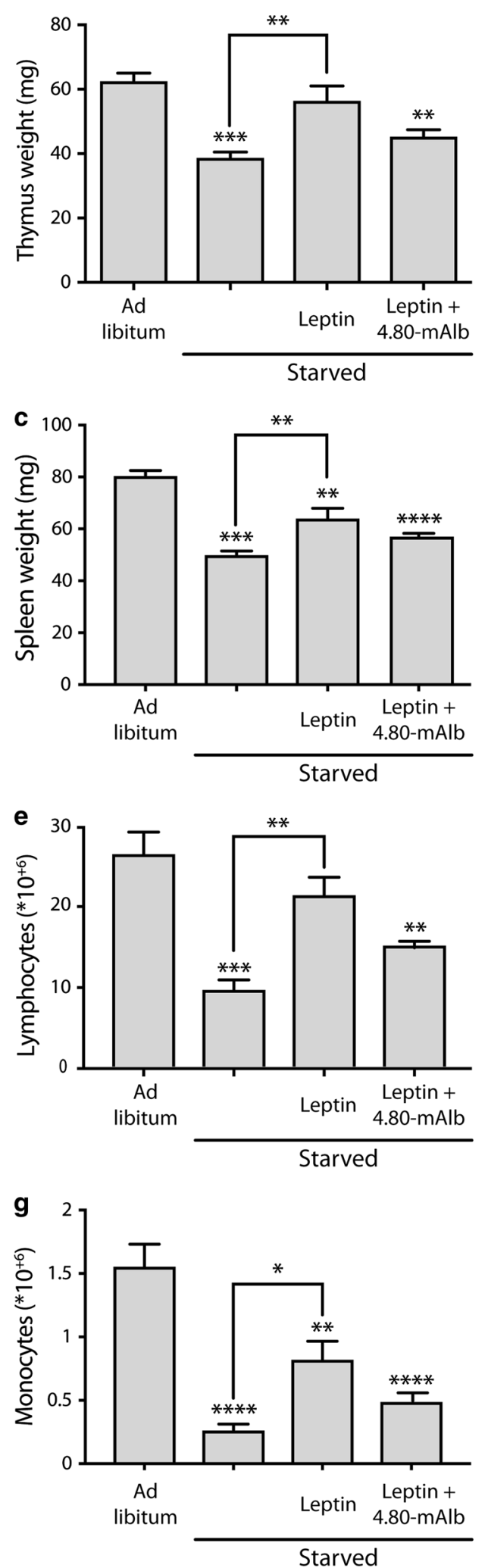
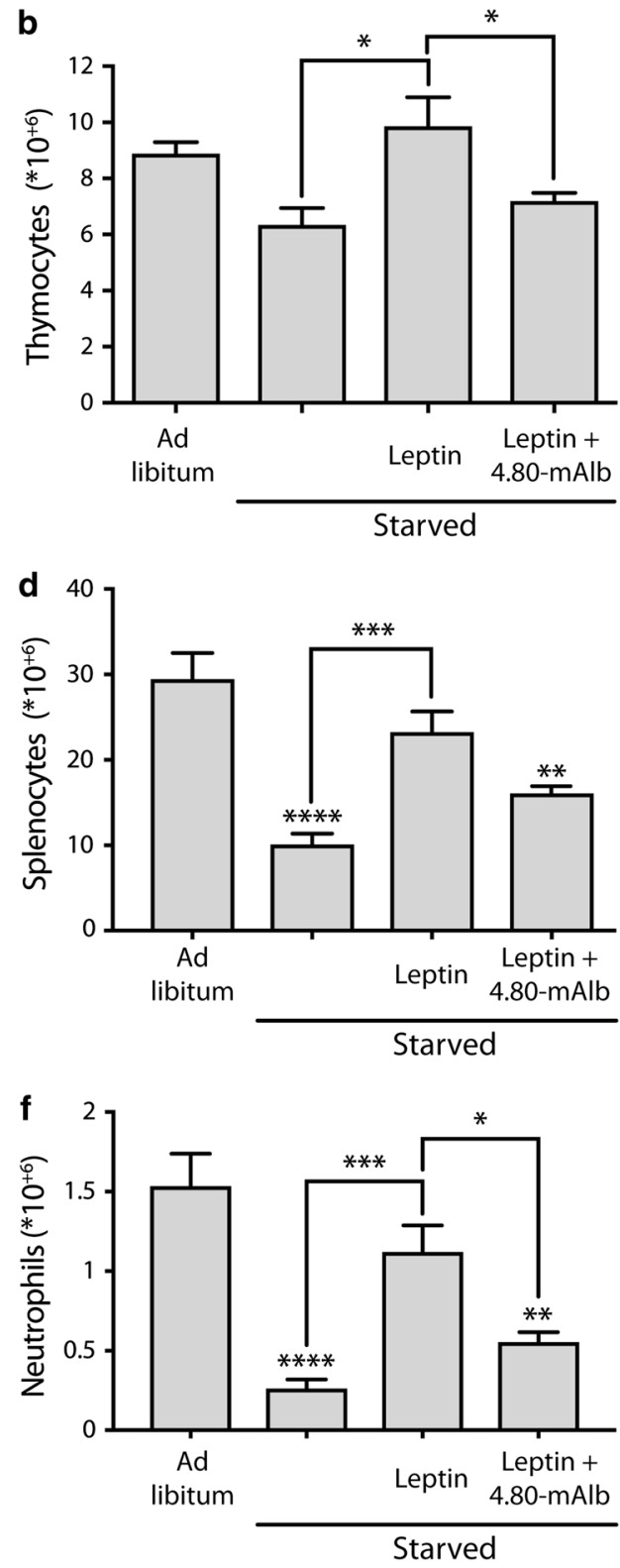

in leptin involved in this interaction resulted in an antagonist both in vitro and in vivo [38, 39]. In strong contrast, we gathered several lines of evidence that LR-mediated immune signalling, but not the control of body weight, can occur in the absence of this interaction: (i) the spontaneous natural S120C mutation in the leptin gene gives rise 
to high incidence of early-onset obesity in the Nochurli population. Surprisingly, affected patients are still fertile and not more susceptible to infections (unpublished data). This latter is in strong contrast to earlier described human loss-of-function mutations in leptin or LR genes [79]. (ii) Fatt/fatt mice carry a spontaneous splice mutation that causes deletion of the complete IGD in all LR isoforms [43]. These animals are hyperphagic and morbidly obese, but, in contrast to other leptin or LR-deficient rodents, display only minimal changes in size and cellularity of the thymus and respond to concavalin A in a model for autoimmune hepatitis. (iii) Treatment of healthy mice with an IGD-specific neutralising VHH induced weight gain and hyperinsulinemia, but failed to block development of experimentally induced autoimmune multiple sclerosis, arthritis and hepatitis [43].

In this study we now show that the leptin S120A-T121A antagonist, which is unable to interact with the LR IGD, is capable of inducing EGFR phosphorylation comparable to wild-type leptin (Fig. 2a). Furthermore, co-expression of EGFR partially restores STAT3-dependent signalling by this mutant through the LR (Fig. 2b). The signalling capacities of the leptin S120A-T121A mutant suggest that the structural requirements for LR signalling vs LR-EGFR cross talk appear to be fundamentally different. To further explore this hypothesis, we evaluated the effect of mouse LR-selective VHHs from a previously designed library [50] on both types of signalling. We found that VHH 4.80, directed against the LR FN III domains, selectively interfered with LR-EGFR cross talk (measured by leptin S120A-T121A-induced STAT3 signalling in LR and EGFR co-transfected cells), but not with canonical LR signalling (leptin stimulation of LR expressing cells)(Fig. 3), while VHH 2.17, which was previously shown to interfere with leptin binding to its cognate receptor [50], clearly blocks both pathways. VHH 4.80 also blocks leptin or leptin S120A-T121A driven EGFR phosphorylation.

In a next step, we compared the effect of the selective VHH 4.80 with previously characterised, neutralising VHHs 2.17 and 4.10 [50] on metabolism in healthy mice. All VHHs were coupled to a mouse serum albuminspecific VHH (mAlb) to prolong half-life in circulation [50]. Both VHH 2.17 and 4.10 treatments resulted in a significant increase in daily food intake, body weight and subcutaneous and visceral fat mass, while a 14-day treatment with VHH 4.80 did not alter these parameters in a significant manner (Fig. 4). This difference could not be explained by a different accumulation of the VHHs in circulation, since VHH 4.80 levels were comparable to $\mathrm{VHH}$ 2.17 levels and higher than VHH 4.10 levels after 2 weeks of treatment. No significant differences in basal blood glucose levels and glucose tolerance were observed between the treated groups, which is in line with the study of Levi et al. where 3 days treatment with a pegylated mouse leptin antagonist (L39A/D40A/F41A) did not alter glucose disposal [80].

The LR-EGFR cross talk could provide a molecular explanation for the LR immune signalling in the absence of the IGD interaction. EGFR is known to be critically involved in tissue development and homeostasis as well as in the pathogenesis of cancer. EGFR antagonists were one of the first anti-cancer treatments developed targeting a receptor tyrosine kinase. Several studies illustrate that a substantial part of the clinical responses observed following EGFR targeting treatments may not only be mediated by direct effects on the tumour, but also by regulation of immune responses, an aspect of EGF biology that remains undervalued [81]. For example, the EGFR is expressed on many immune cells including macrophages [82], monocytes [83], plasma cells [84] and some T cell subsets such as effector $\mathrm{CD}^{+} \mathrm{T}$ cells and FoxP3-expressing Treg cells [85], thereby guiding the cellular functionality. The observation that VHH 4.80 blocks leptin-driven EGFR phosphorylation and the partial restoration of signalling by leptin S120A-T121A upon LR-EGFR co-expression prompted us to study the role of LR-EGFR cross talk in vivo. We could show that VHH 4.80, at least in part, reverses the leptin-driven protection against starvation-induced thymic and splenic atrophy measured by cellularity and weight of these organs (Fig. 5). In line with the latter, starvation conditions also severely decrease the number of lymphocytes, neutrophils and monocytes, and leptin reverses those effects, while VHH 4.80 interferes with the leptininduced normalisation of these immune cellular counts.

Together, our data show that the structural requirements for signalling via the LR or LR-EGFR cross talk are fundamentally different. Based on this observation we were able to identify a VHH that selectively inhibits the cross talk, but not the canonical LR activation mechanism. Daily administration of this VHH apparently did not alter any of the tested metabolic parameters, but had significant effects on leptin signalling in the immune compartment as observed in our starvation experiments. Leptin and LR antagonists (leptin mutants, leptin-derived peptides, neutralising antibodies and soluble LR variants) were shown to have a clear potential as therapeutics for the treatment of several autoimmune diseases and cancer [9]. However, the major drawback of most, if not all, current leptin and LR antagonistic strategies is that they also give rise to considerable undesirable weight gain. Uncoupling of leptin's metabolic and immune functions, for example based on the EGFR cross talk, might revitalise the potential of leptin and LR antagonists as a therapeutic strategy.

Acknowledgements This work was supported by a European Research Council (ERC) Advanced Grant (CYRE-No. 340941 (JT)) 
and by grants from the «Agence Nationale de la Recherche » ANR15-CE14-0025 (JD \& RJ), the département hospitalo-universitaire (DHU) «autoimmune and hormonal diseases ", the "Who am I?" laboratory of excellence No. ANR-11-LABX-0071 (JD).

\section{Compliance with ethical standards}

Conflict of Interests The authors declare that they have no conflict of interest.

Open Access This article is distributed under the terms of the Creative Commons Attribution 4.0 International License (http://creativeco mmons.org/licenses/by/4.0/), which permits unrestricted use, distribution, and reproduction in any medium, provided you give appropriate credit to the original author(s) and the source, provide a link to the Creative Commons license, and indicate if changes were made.

\section{References}

1. Considine RV, Sinha MK, Heiman ML et al (1996) Serum immunoreactive-leptin concentrations in normal-weight and obese humans. N Engl J Med 334:292-295

2. Maffei M, Halaas J, Ravussin E et al (1995) Leptin levels in human and rodent: measurement of plasma leptin and ob RNA in obese and weight-reduced subjects. Nat Med 1:1155-1161

3. Friedman JM, Halaas JL (1998) Leptin and the regulation of body weight in mammals. Nature 395:763-770. https://doi. org/10.1038/27376

4. Bennett BD, Solar GP, Yuan JQ et al. (1996) A role for leptin and its cognate receptor in hematopoiesis. Curr Biol 6:1170-1180. https://doi.org/10.1016/S0960-9822(02)70684-2

5. Francisco V, Pino J, Campos-cabaleiro V et al (2018) Obesity, fat mass and immune system: role for leptin. Front Physiol 9:1-20. https://doi.org/10.3389/fphys.2018.00640

6. Naylor C, Petri WA (2016) Leptin regulation of immune responses. Trends Mol Med 22:88-98. https://doi.org/10.1016/j. molmed.2015.12.001

7. Carbone F, La Rocca C, Matarese G (2012) Immunological functions of leptin and adiponectin. Biochimie 94:2082-2088. https ://doi.org/10.1016/j.biochi.2012.05.018

8. Fantuzzi G (2009) Three questions about leptin and immunity. Brain Behav Immun 23:405-410. https://doi.org/10.1016/j. bbi.2008.10.007

9. Zabeau L, Peelman F, Tavernier J (2014) Antagonising leptin: current status and future directions. Biol Chem 395:499-514. https:// doi.org/10.1515/hsz-2013-0283

10. Chehab FF, Lim ME, Lu R (1996) Correction of the sterility defect in homozygous obese female mice by treatment with the human recombinant leptin. Nat Genet 12:318-320. https://doi. org/10.1038/ng0396-318

11. Briffa JF, McAinch AJ, Romano T et al (2015) Leptin in pregnancy and development: a contributor to adulthood disease? Am J Physiol Endocrinol Metab 308(5):E335-E350. https://doi. org/10.1152/ajpendo.00312.2014

12. Sierra-Honigmann MR, Nath AK, Murakami C et al (1998) Biological action of leptin as an angiogenic factor. Science 281:1683-1686

13. Konstantinides S, Schafer K, Koschnick S, Loskutoff D (2001) Leptin-dependent platelet aggregation and arterial thrombosis suggests a mechanism for atherothrombotic disease in obesity. $\mathrm{J}$ Clin Invest 108:1533-1540
14. Mark AL, Shaffer RA, Correia ML et al (1999) Contrasting blood pressure effects of obesity in leptin-deficient ob/ob mice and agouti yellow obese mice. J Hypertens 17:1949-1953

15. Ducy P, Amling M, Takeda S et al (2000) Leptin inhibits bone formation through a hypothalamic relay: a central control of bone mass. Cell 100:197-207

16. Farooqi IS, Matarese G, Lord GM et al (2002) Beneficial effects of leptin on obesity, T cell hyporesponsiveness, and neuroendocrine/ metabolic dysfunction of human congenital leptin deficiency. $\mathrm{J}$ Clin Invest 110:1093-1103. https://doi.org/10.1172/JCI15693

17. Matarese G, La Cava A, Sanna V et al (2002) Balancing susceptibility to infection and autoimmunity: a role for leptin? Trends Immunol 23:182-187

18. Procaccini C, La C, Carbone F et al (2017) Leptin as immune mediator: interaction between neuroendocrine and immune system. Dev Comp Immunol 66:120-129. https://doi.org/10.1016/j. dci.2016.06.006

19. Karmiris K, Koutroubakis IE, Kouroumalis EA (2008) Leptin, adiponectin, resistin, and ghrelin-implications for inflammatory bowel disease. Mol Nutr Food Res 52:855-866. https://doi. org/10.1002/mnfr.200700050

20. Karmiris K, Koutroubakis IE, Kouroumalis EA (2005) The emerging role of adipocytokines as inflammatory mediators in inflammatory bowel disease. Inflamm Bowel Dis 11:847-855. https://doi.org/10.1097/01.mib.0000178915.54264.8f

21. Navarini L, Margiotta DPE, Vadacca M, Afeltra A (2018) Leptin in autoimmune mechanisms of systemic rheumatic diseases. Cancer Lett 423:139-146. https://doi.org/10.1016/j.canle t.2018.03.011

22. Busso N, So A, Chobaz-Peclat V et al (2002) Leptin signaling deficiency impairs humoral and cellular immune responses and attenuates experimental arthritis. J Immunol 168:875-882

23. Matarese G, Di Giacomo A, Sanna V et al (2001) Requirement for leptin in the induction and progression of autoimmune encephalomyelitis. J Immunol 166:5909-5916

24. Matarese G, Carrieri PB, La Cava A et al (2005) Leptin increase in multiple sclerosis associates with reduced number of CD4(+) CD25 + regulatory T cells. Proc Natl Acad Sci USA 102:51505155. https://doi.org/10.1073/pnas.0408995102

25. Faggioni R, Jones-Carson J, Reed DA et al (2000) Leptin-deficient (ob/ob) mice are protected from $\mathrm{T}$ cell-mediated hepatotoxicity: role of tumor necrosis factor alpha and IL-18. Proc Natl Acad Sci USA 97:2367-2372. https://doi.org/10.1073/ pnas.040561297040561297

26. Sennello JA, Fayad R, Morris AM et al (2005) Regulation of $\mathrm{T}$ cell-mediated hepatic inflammation by adiponectin and leptin. Endocrinology 146:2157-2164. https://doi.org/10.1210/ en.2004-1572

27. Siegmund B, Lear-Kaul KC, Faggioni R, Fantuzzi G (2002) Leptin deficiency, not obesity, protects mice from Con A-induced hepatitis. Eur J Immunol 32:552-560

28. Garofalo C, Surmacz E (2006) Leptin and cancer. J Cell Physiol 207:12-22. https://doi.org/10.1002/jcp.20472

29. Ray A, Cleary MP (2010) Leptin as a potential therapeutic target for breast cancer prevention and treatment. Expert Opin Ther Targets 14:443-451. https://doi.org/10.1517/147282210037164 66

30. Cirillo D, Rachiglio AM, la Montagna R et al (2008) Leptin signaling in breast cancer: an overview. J Cell Biochem 105:956-964. https://doi.org/10.1002/jcb.21911

31. Pais R, Silaghi H, Silaghi A-C et al (2009) Metabolic syndrome and risk of subsequent colorectal cancer. World J Gastroenterol 15:5141-5148

32. Liao LM, Schwartz K, Pollak M et al (2013) Serum leptin and adiponectin levels and risk of renal cell carcinoma. Obesity (Silver Spring) 21:1478-1485. https://doi.org/10.1002/oby.20138 
33. Favreau M, Menu E, Gaublomme D et al (2017) Leptin receptor antagonism of iNKT cell function: a novel strategy to combat multiple myeloma. Leukemia 146:1-8. https://doi.org/10.1038/ leu.2017.146

34. Gogas H, Trakatelli M, Dessypris N et al (2008) Melanoma risk in association with serum leptin levels and lifestyle parameters: a case-control study. Ann Oncol 19:384-389. https://doi. org/10.1093/annonc/mdm464

35. Tartaglia LA, Dembski M, Weng X et al (1995) Identification and expression cloning of a leptin receptor. Cell 83:1263-1271. https ://doi.org/10.1016/0092-8674(95)90151-5

36. Fong TM, Huang RR, Tota MR et al (1998) Localization of leptin binding domain in the leptin receptor. Mol Pharmacol 53:234-240

37. Zabeau L, Defeau D, Van der Heyden J et al (2004) Functional analysis of leptin receptor activation using a Janus kinase/signal transducer and activator of transcription complementation assay. Mol Endocrinol 18:150-161. https://doi.org/10.1210/ Me.2003-0078

38. Peelman F, Van Beneden K, Zabeau L et al (2004) Mapping of the leptin binding sites and design of a leptin antagonist. J Biol Chem 279:41038-41046. https://doi.org/10.1074/jbc.M404962200

39. Niv-Spector L, Gonen-Berger D, Gourdou I et al (2005) Identification of the hydrophobic strand in the A-B loop of leptin as major binding site III: implications for large-scale preparation of potent recombinant human and ovine leptin antagonists. Biochem J 391:221-230. https://doi.org/10.1042/bj20050457

40. Ghilardi N, Skoda RC (1997) The leptin receptor activates janus kinase 2 and signals for proliferation in a factor-dependent cell line. Mol Endocrinol 11:393-399

41. Wauman J, Zabeau L, Tavernier J (2017) The leptin receptor complex: heavier than expected? Front Endocrinol (Lausanne) 8:30. https://doi.org/10.3389/fendo.2017.00030

42. Wauman J, Tavernier J (2011) Leptin receptor signaling: pathways to leptin resistance. Front Biosci 16:2771-2793. https://doi. org/10.2741/3885

43. Zabeau L, Jensen CJ, Seeuws S et al (2015) Leptin's metabolic and immune functions can be uncoupled at the ligand/receptor interaction level. Cell Mol Life Sci 72:629-644. https://doi.org/10.1007/ s00018-014-1697-x

44. Ozbay T, Nahta R (2008) A novel unidirectional cross-talk from the insulin-like growth factor-I receptor to leptin receptor in human breast cancer cells. Mol Cancer Res 6:1052-1058. https:// doi.org/10.1158/1541-7786.MCR-07-2126

45. Saxena NK, Taliaferro-Smith L, Knight BB et al (2008) Bidirectional crosstalk between leptin and insulin-like growth factorI signaling promotes invasion and migration of breast cancer cells via transactivation of epidermal growth factor receptor. Cancer Res 68:9712-9722. https://doi.org/10.1158/0008-5472. CAN-08-1952

46. Chao H-H, Hong H-J, Liu J-C et al (2007) Leptin stimulates endothelin-1 expression via extracellular signal-regulated kinase by epidermal growth factor receptor transactivation in rat aortic smooth muscle cells. Eur J Pharmacol 573:49-54. https://doi. org/10.1016/j.ejphar.2007.06.051

47. Ogunwobi O, Mutungi G, Beales ILP (2006) Leptin stimulates proliferation and inhibits apoptosis in Barrett's esophageal adenocarcinoma cells by cyclooxygenase-2-dependent, prostaglandinE2-mediated transactivation of the epidermal growth factor receptor and c-Jun NH2-terminal kinase activation. Endocrinology 147:4505-4516. https://doi.org/10.1210/en.2006-0224

48. Fusco R, Galgani M, Procaccini C et al (2010) Cellular and molecular crosstalk between leptin receptor and estrogen receptor alpha in breast cancer: molecular basis for a novel therapeutic setting. Endocr Relat Cancer 17:373-382. https://doi.org/10.1677/ ERC-09-0340
49. Binai NA, Damert A, Carra G et al (2010) Expression of estrogen receptor alpha increases leptin-induced STAT3 activity in breast cancer cells. Int J Cancer 127:55-66. https://doi.org/10.1002/ ijc. 25010

50. Zabeau L, Verhee A, Catteeuw D et al (2012) Selection of noncompetitive leptin antagonists using a random nanobody-based approach. Biochem J 441:425-434. https://doi.org/10.1042/BJ201 10438

51. Broekaert D, Eyckerman S, Lavens D et al (2002) Comparison of leptin- and interleukin-6-regulated expression of the rPAP gene family: evidence for differential co-regulatory signals. Eur Cytokine Netw 13:78-85

52. Vauthier V, Derviaux C, Douayry N et al (2013) Design and validation of a homogeneous time-resolved fluorescence-based leptin receptor binding assay. Anal Biochem 436:1-9. https:// doi.org/10.1016/j.ab.2012.12.013

53. Cottet M, Faklaris O, Maurel D et al (2012) BRET and Timeresolved FRET strategy to study GPCR oligomerization: from cell lines toward native tissues. Front Endocrinol (Lausanne) 3:92. https://doi.org/10.3389/fendo.2012.00092

54. Lievens S, Gerlo S, Lemmens I et al (2014) Kinase substrate sensor (KISS), a Mammalian in situ protein interaction sensor. Mol Cell Proteomics 13:3332-3342

55. Fujita Y, Murakami M, Ogawa Y et al (2002) Leptin inhibits stress-induced apoptosis of T lymphocytes. Clin Exp Immunol 128:21-26

56. Tanaka M, Suganami T, Kim-Saijo M et al (2011) Role of central leptin signaling in the starvation-induced alteration of B-cell development. J Neurosci 31:8373-8380. https://doi. org/10.1523/JNEUROSCI.6562-10.2011

57. Lord GM, Matarese G, Howard JK et al (1998) Leptin modulates the T-cell immune response and reverses starvationinduced immunosuppression. Nature 394:897-901. https://doi. org/10.1038/29795

58. Howard JK, Lord GM, Matarese G et al (1999) Leptin protects mice from starvation-induced lymphoid atrophy and increases thymic cellularity in ob/ob mice. J Clin Invest 104:1051-1059. https://doi.org/10.1172/JCI6762

59. Livnah O, Stura EA, Middleton SA et al (1999) Crystallographic evidence for preformed dimers of erythropoietin receptor before ligand activation. Science 283:987-990

60. Gent J, van Kerkhof P, Roza M et al (2002) Ligand-independent growth hormone receptor dimerization occurs in the endoplasmic reticulum and is required for ubiquitin system-dependent endocytosis. Proc Natl Acad Sci USA 99:9858-9863. https:// doi.org/10.1073/pnas.152294299

61. Schuster B, Meinert W, Rose-John S, Kallen K-J (2003) The human interleukin-6 (IL-6) receptor exists as a preformed dimer in the plasma membrane. FEBS Lett 538:113-116

62. Tao R-H, Maruyama IN (2008) All EGF(ErbB) receptors have preformed homo- and heterodimeric structures in living cells. J Cell Sci 121:3207-3217. https://doi.org/10.1242/jcs.033399

63. Yu X, Sharma KD, Takahashi T et al (2002) Ligand-independent dimer formation of epidermal growth factor receptor (EGFR) is a step separable from ligand-induced EGFR signaling. Mol Biol Cell 13:2547-2557. https://doi.org/10.1091/mbc.01-08-0411

64. Couturier C, Jockers R (2003) Activation of the leptin receptor by a ligand-induced conformational change of constitutive receptor dimers. J Biol Chem 278:26604-26611. https://doi. org/10.1074/jbc.M302002200M302002200

65. Ramanujan VK, Biener E, Charlier M et al (2005) Quantitative FRET imaging of leptin receptor oligomerization kinetics in single cells. Microsc Microanal 11:11-12. https://doi. org/10.1017/S1431927605505907 
66. Nakashima K, Narazaki M, Taga T (1997) Leptin receptor (OB-R) oligomerizes with itself but not with its closely related cytokine signal transducer gp130. FEBS Lett 403:79-82

67. White DW, Tartaglia LA (1999) Evidence for ligand-independent homo-oligomerization of leptin receptor (OB-R) isoforms: a proposed mechanism permitting productive long-form signaling in the presence of excess short-form expression. J Cell Biochem 73:278-288

68. Zabeau L, Defeau D, Iserentant H et al (2005) Leptin receptor activation depends on critical cysteine residues in its fibronectin type III subdomains. J Biol Chem 280:22632-22640. https://doi. org/10.1074/jbc.m413308200

69. Eisenberg A, Biener E, Charlier M et al (2004) Transactivation of erbB2 by short and long isoforms of leptin receptors. FEBS Lett 565:139-142. https://doi.org/10.1016/j.febslet.2004.03.089

70. Beltowski J, Jazmroz-Wisniewska A (2014) Transactivation of ErbB receptors by leptin in the cardiovascular system: mechanisms, consequences and target for therapy. Curr Pharm Des 20:616-624

71. Köse M (2017) GPCRs and EGFR - cross-talk of membrane receptors in cancer. Bioorg Med Chem Lett 27:3611-3620. https ://doi.org/10.1016/j.bmcl.2017.07.002

72. Wang $Z$ (2016) Transactivation of epidermal growth factor receptor by $\mathrm{G}$ protein-coupled receptors: recent progress, challenges and future research. Int J Mol Sci 17:95. https://doi.org/10.3390/ ijms17010095

73. Yamaguchi H, Chang S-S, Hsu JL, Hung M-C (2014) Signaling cross-talk in the resistance to HER family receptor targeted therapy. Oncogene 33:1073-1081. https://doi.org/10.1038/ onc. 2013.74

74. Singh B, Carpenter G, Coffey RJ (2016) EGF receptor ligands: recent advances. F1000Res 5:2270. https://doi.org/10.12688/ f1000research.9025.1

75. Roskoski R (2014) The ErbB/HER family of protein-tyrosine kinases and cancer. Pharmacol Res 79:34-74. https://doi. org/10.1016/J.PHRS.2013.11.002

76. Wee P, Wang Z (2017) Epidermal Growth Factor Receptor Cell Proliferation Signaling Pathways. Cancers (Basal) 9:52. https:// doi.org/10.3390/cancers 9050052
77. Ishikawa M, Kitayama J, Nagawa H (2004) Enhanced expression of leptin and leptin receptor (OB-R) in human breast cancer. Clin Cancer Res 10:4325-4331

78. Knight BB, Oprea-Ilies GM, Nagalingam A et al (2011) Survivin upregulation, dependent on leptin-EGFR-Notch1 axis, is essential for leptin-induced migration of breast carcinoma cells. Endocr Relat Cancer 18:413-428. https://doi.org/10.1530/ERC-11-0075

79. Farooqi IS, O'Rahilly S (2014) 20 years of leptin: human disorders of leptin action. J Endocrinol 223:T63-T70. https://doi. org/10.1530/JOE-14-0480

80. Levi J, Gray SL, Speck M et al (2011) Acute disruption of leptin signaling in vivo leads to increased insulin levels and insulin resistance. Endocrinology 152:3385-3395

81. Ferris RL, Jaffee EM, Ferrone S (2010) Tumor antigen-targeted, monoclonal antibody-based immunotherapy: clinical response, cellular immunity, and immunoescape. J Clin Oncol 28:4390 4399. https://doi.org/10.1200/JCO.2009.27.6360

82. Scholes AG, Hagan S, Hiscott $P$ et al (2001) Overexpression of epidermal growth factor receptor restricted to macrophages in uveal melanoma. Arch Ophthalmol 119:373-377

83. Chan G, Nogalski MT, Yurochko AD (2009) Activation of EGFR on monocytes is required for human cytomegalovirus entry and mediates cellular motility. Proc Natl Acad Sci USA 106:2236922374. https://doi.org/10.1073/pnas.0908787106

84. Mahtouk K, Hose D, Rème T et al (2005) Expression of EGF-family receptors and amphiregulin in multiple myeloma. Amphiregulin is a growth factor for myeloma cells. Oncogene 24:3512-3524. https://doi.org/10.1038/sj.onc.1208536

85. Zaiss DMW, van Loosdregt J, Gorlani A et al (2013) Amphiregulin enhances regulatory $\mathrm{T}$ cell-suppressive function via the epidermal growth factor receptor. Immunity 38:275-284. https://doi. org/10.1016/j.immuni.2012.09.023

Publisher's Note Springer Nature remains neutral with regard to jurisdictional claims in published maps and institutional affiliations. 